\title{
Consumers' various and surprising responses to direct-to-consumer advertisements in magazine print
}

This article was published in the following Dove Press journal:

Patient Preference and Adherence

21 January 2013

Number of times this article has been viewed

\author{
Jennifer Arney ${ }^{1-3}$ \\ Richard L Street Jr $\mathrm{r}^{2-4}$ \\ Aanand D Naik ${ }^{2,3}$ \\ 'Department of Sociology, University \\ of Houston - Clear Lake, ${ }^{2}$ Houston \\ VA Health Services Research \\ and Development Center of \\ Excellence, Michael E DeBakey \\ Department of Veterans Affairs \\ Medical Center, ${ }^{3}$ Section on Health \\ Services Research, Baylor College \\ of Medicine, Houston, ${ }^{4}$ Department \\ of Communication, Texas A\&M \\ University, College Station, TX, USA
}

Correspondence: Jennifer Arney Department of Sociology, University of Houston - Clear Lake, 2700 Bay Area Blvd, Houston, TX 77058, USA

Tel + I 28I 283344 I

Email arney@uhcl.edu
Abstract: Direct-to-consumer advertising (DTCA) is ubiquitous in media outlets, but little is known about the ways in which consumers' values, needs, beliefs, and biases influence the perceived meaning and value of DTCA. This article aims to identify the taxonomy of readership categories that reflect the complexity of how health care consumers interact with DTCA, with particular focus on individuals' perceptions of print DTCA in popular magazines. Respondentdriven sampling was used to recruit 18 male and female magazine readers and 18 male and female prescription medication users aged 18-71 years. Semi-structured, in-depth interviews with consumers about their attentiveness, motivations, perceived value, and behavioral responses to DTCA were conducted. The analyses were guided by principles of grounded theory analysis; four categories that vary in consumers' attentiveness, motivations, perceived value, and behavioral responses to DTCA were identified. Two categories - the lay physician and the informed shopper - see value in information from DTCA and are likely to seek medical care based on the information. One category - the voyeur - reads DTCA, but is not likely to approach a clinician regarding advertised information. The fourth category - the evader - ignores DTCA and is not likely to approach a clinician with DTCA information. Responses to DTCA vary considerably among consumers, and physicians should view patients' understanding and response to DTCA within the context of their health-related needs. Patients' comments related to DTCA may be used as an opportunity to engage and understand patients' perspectives about illness and medication use. Clinicians may use information about these categories to facilitate shared understanding and improve communication within the doctor-patient relationship.

Keywords: communication, decision making, doctor-patient relationships, qualitative research

\section{Introduction}

Direct-to-consumer advertising (DTCA) describes the phenomenon by which pharmaceutical manufacturers promote their products directly toward consumer audiences. Some studies report that health care consumers view DTCA favorably, claiming that the materials are educational, provide useful information about health conditions and available treatments, and give patients confidence and a sense of control in medical encounters. ${ }^{1-8}$ On the other hand, DTCA has been criticized for its propensity to undermine the authority of medical professionals, weaken the physician-patient relationship, produce conflict in medical encounters, and influence patients to pressure physicians. ${ }^{9-17}$ Medical encounters in which DTCA is discussed may result in clinically unnecessary requests for tests, referrals to specialists, alterations in medications, and inappropriate prescribing of new and expensive drugs. ${ }^{18,19}$ 
Those who fear that DTCA unduly influences patients' health beliefs and treatment preferences tend to embrace a deterministic view of the effect of media on audience behavior. In actuality, media consumers are active information processors who seek and retain information given their motivations and needs and who will rely on multiple information sources such as media, family, and physicians. ${ }^{20}$ While media content can influence how people think about an issue, consumers create meaning from information, given its perceived relevance and their prior knowledge about a topic. ${ }^{21} \mathrm{~A}$ recent survey of members of an online depression forum revealed that the majority of those surveyed rated information in DTCA as "poor" or "fair;" however, some respondents sought further information about advertised products after viewing DTCA.22 Thus, consumers' evaluations of DTCA and their advertisement-driven behaviors are quite complex.

The objective of this study was to identify the taxonomy of readership categories that reflect the complexity of health care consumers' interactions with DTCA as it relates to clinical decision making and motivations for their behaviors. Knowledge of readership categories will offer physicians a better understanding of the various ways patients respond to DTCA, and how these responses potentially shape patients' preferences and behavioral intentions. Awareness of the factors that shape patients' preference could improve trust and shared understanding within the doctor-patient relationship. ${ }^{23-27}$ It has been previously shown how collaborative and proactive discussion with patients improves adherence to therapy and health outcomes..$^{28-30}$ This study builds upon previous research to offer physicians information that may be used in clinical encounters to achieve such collaborative discussions. These issues are looked at within the context of pharmacological agents for treating psychiatric illness (depression and anxiety) because of the prevalence of affective disorders in the population, the high frequency of antidepressant drug use, and the ubiquity of pharmaceutical advertisements for this category of medication. Additionally, print media may be an effective outlet for advertising, as this medium may facilitate information scanning among targeted groups. Thus, advertising messages may be absorbed even when consumers are not necessarily seeking the information. ${ }^{31}$

\section{Methods}

\section{Sample and study design}

Semi-structured, in-depth qualitative interviews were used to assess health care consumers' utilization of and interaction with print DTCA. Recruitment efforts focused on two types of consumers: magazine readers familiar with print DTCA and antidepressant medication users. These two populations were chosen because of their different but heightened relationships with DTCA. It was expected that magazine readers would by definition have greater exposure to print DTCA than the general population, and thus could comment on their perceptions of pharmaceutical advertising. Antidepressant users were recruited because it was expected that antidepressant DTCA would be more salient to this group of individuals. Participants were prescribed antidepressant medications for various conditions, including major depressive disorder, social anxiety disorder, and chronic pain (ie, associated with fibromyalgia). Participants had used antidepressants from 3 months to 22 years (median duration of use $=8.8$ years). Sample characteristics are located in Table 1. All subjects were English speakers, aged 18 years or older, who were willing and able to discuss their attention to and perception of pharmaceutical advertising.

Participants were identified using snowball ${ }^{32}$ or chainreferral sampling, ${ }^{33-35}$ a variant of nonprobability purposive sampling. Initial participants were accessed through "street outreach"36 - in this case, via fliers posted in community centers, public libraries, churches, coffee shops, and supermarkets. Fliers specified the interest in speaking with women and men over the age of 18 years who either use antidepressants or regularly read selected popular magazines. This strategy allowed the recruitment of antidepressant users who were familiar with DTCA but were not necessarily magazine readers, as well as magazine readers who did not use antidepressant medications. Once participants completed the interview, they were then asked to recruit other potential participants who met the study criteria. Snowball sampling was chosen to locate the sample of antidepressant users because, due to the stigma associated with affective disorder and the tendency for antidepressant users to keep private their antidepressant use, this group can be considered a hidden population. This research was approved by a university institutional review board and all subjects received and signed an institutional review board-authorized

Table I Sample characteristics by category

\begin{tabular}{lll}
\hline Sex & Number & $\begin{array}{l}\text { Age, years } \\
\text { Median (range) }\end{array}$ \\
\hline $\begin{array}{lll}\text { Antidepressant users } \\
\text { Women }\end{array}$ & 11 & $37(18-58)$ \\
Men & 7 & $36(30-61)$ \\
Magazine readers & & \\
Women & 9 & $29(24-71)$ \\
Men & 9 & $36(25-66)$ \\
\hline
\end{tabular}


letter detailing the goals, benefits, and potential risks of the study. In-depth interviews, ranging from 25-112 minutes, were conducted in person by the lead author (JA) at a public location of the participant's choice. All interviews were recorded, transcribed, and analyzed for content.

The semi-structured, open-ended interviews were guided by four broad interview questions, which were designed to ascertain consumers' utilization of and opinions concerning print DTCA. Interview participants were asked:

1. How often do you take time to read DTCA?

2. What determines whether or not you read a drug advertisement?

3. Is the information in DTCA useful? How do you use the information?

4. Have you ever acted on information you read in DTCA? For instance, based on something you read in an ad, have you ever looked for more information or consulted a physician?

\section{Analysis}

Principles of grounded theory analysis were applied in order to generate theory that most effectively fits the data and to safeguard against the use of theories that may imprecisely correspond with the data. This form of analysis facilitates the development of coding categories based on themes that emerge within a data set. ${ }^{37-39}$ Grounded theory analysis is a popular analytical approach in qualitative inquiry, and has been used in previous patient-centered medical research. ${ }^{40,41}$ Analysis of interviews began during data collection and data were categorized as they amassed. Initially, an "open coding” procedure was applied, ${ }^{38}$ which involved the examination of each interview transcript and the categorization of phenomena therein in order to identify a preliminary set of themes in the data set. Extensive memos were written during this procedure in order to refine and broaden thematic categories. The lead author (JA) applied the "open coding" procedure, and the research team then discussed the emergent themes and contributed to subsequent coding procedures. As additional interviews were conducted, content became increasingly focused toward established themes, but remained flexible enough to facilitate the emergence of additional concepts. "Selective coding" was used to examine each transcript for specific examples of the preliminary themes. All three authors reviewed the interview data, and any disagreements in coding were discussed and resolved. Respondents continued to be interviewed until thematic saturation was reached, ie, when the domains of interest had been fully sampled, the data were rich, full, and complete, and it was determined that additional interviews would render no new insights. ${ }^{42}$ Thematic saturation was reached after 36 interviews.

The coding procedure resulted in four themes that reflect the combined attitudes and opinions of antidepressant users and magazine readers. These themes allowed for the classification of respondents into assorted consumer categories.

1. Attentiveness: references to familiarity and attention to DTCA are included in this theme. This includes comments regarding whether or not respondents read DTCA and what portion of individual advertisements they typically read.

2. Motivations: explanations for readership behaviors are included in this theme.

3. Value of advertising messages: references to DTCA's utility or lack thereof are included in this theme. This also includes comments regarding how DTCA meets, or fails to meet, respondents' individual needs.

4. Behavioral responses: references to ways respondents use information in DTCA are included in this theme. For instance, references to searching for further information about a medication or condition, seeking medical advice, or suggesting others seek medical advice based on DTCA are included.

\section{Results}

The interviews reflect a variety of consumer categories that describe interactions with DTCA. Analysis resulted in the development of two simple readership categories: those who pay attention to DTCA and those who do not. These categories are further classified based on participants' reported motivations, perceived value, and responses to DTCA. Table 2 describes the four categories of consumers' responses to DTCA. The group of DTCA consumers is comprised of three categories - the lay physician, the informed shopper, and the voyeur - and those who ignore DTCA are classified as evaders.

\section{Consumer categories}

\section{The lay physician}

Lay physicians use information in DTCA to diagnose themselves and others. These consumers read diagnostic criteria with themselves and loved ones in mind, and may use the information in medical encounters to present a case for specific diagnoses and drug therapies. Both, magazine readers and antidepressant medication users comprise the category of lay physicians. One male magazine reader, 28-year-old RF, learned about social anxiety disorder through DTCA and believes that he fits the criteria. He recalls seeing an advertisement "for social anxiety that I watched a little 
Table 2 Consumer categories and quotations

\begin{tabular}{|c|c|c|c|}
\hline \multicolumn{3}{|l|}{ DTCA readers } & \multirow{2}{*}{$\begin{array}{l}\text { Nonreaders } \\
\text { Evader }\end{array}$} \\
\hline Lay physician & Informed shopper & Voyeur & \\
\hline Diagnoses self and others & $\begin{array}{l}\text { Makes decisions about treatment } \\
\text { options }\end{array}$ & Is curious about illnesses & $\begin{array}{l}\text { Believes DTCA is biased } \\
\text { or irrelevant }\end{array}$ \\
\hline $\begin{array}{l}\text { Those ads existing say that } \\
\text { there're people out there - } \\
\text { possibly you're one of them - } \\
\text { that have these problems. "Do } \\
\text { you do these things?" } \\
\text { [MR, } 45 \text {-year-old female } \\
\text { magazine reader] }\end{array}$ & $\begin{array}{l}\text { If you're taking something and } \\
\text { you see it advertised, it's like if you } \\
\text { buy a car and you see a really nice } \\
\text { advertisement for that car and you } \\
\text { think, "Oh I have that car, what } \\
\text { a great car." It's sort of like, I'm } \\
\text { assured that it's a good drug } \\
\text { because I see it advertised. } \\
\text { [KB, 58-year-old female } \\
\text { medication user] }\end{array}$ & $\begin{array}{l}\text { I have read [DTCA] for ADD } \\
\text { because I'm not familiar with } \\
\text { that. I've never had that disorder. } \\
\text { Obsessive compulsive disorder, if } \\
\text { I see an ad for something like that } \\
\text { I might read it, just because I'm } \\
\text { not familiar with it and I want } \\
\text { to educate myself about mood } \\
\text { disorders, other than the ones } \\
\text { I have. [TB, 39-year-old male } \\
\text { medication user] }\end{array}$ & $\begin{array}{l}\text { [DTCA] is kind of pointless [...] } \\
\text { The doctor knows how to diagnose } \\
\text { an illness and I don't, so why should } \\
\text { I be the one thinking I should make } \\
\text { the decision? I like to make an } \\
\text { informed decision, but that's } \\
\text { different. I get into things like } \\
\text { Web MD. This is stuff I look at, } \\
\text { not an ad. [RH, 34-year-old } \\
\text { male magazine reader] }\end{array}$ \\
\hline $\begin{array}{l}\text { If I knew someone I thought } \\
\text { could benefit from the } \\
\text { medication, I might say, "Hey, } \\
\text { maybe you should take a look } \\
\text { at this."[AM, 24-year-old } \\
\text { female magazine reader] }\end{array}$ & $\begin{array}{l}\text { If you tried one medication and } \\
\text { it's not working [through DTCA] } \\
\text { you'll find out there's another } \\
\text { one you can take. [J], 37-year-old } \\
\text { female medication user] }\end{array}$ & $\begin{array}{l}\text { [DTCA] is interesting. If you're } \\
\text { reading Cosmo, you want to read } \\
\text { the advice column. It's stress- } \\
\text { relieving to see how screwed up } \\
\text { everybody's life is. It's the same } \\
\text { as reading an advice column, } \\
\text { finding out what's going on in } \\
\text { the pulse of people's psyche. } \\
\text { [JG, } 29 \text {-year-old female magazine } \\
\text { reader] }\end{array}$ & $\begin{array}{l}\text { I'll just flip the page. I'm not the } \\
\text { kind of person who's always looking } \\
\text { for something to be wrong, so the } \\
\text { information in ads is just not really } \\
\text { anything l'm interested in. [BD, } 40 \text { - } \\
\text { year-old male medication user] }\end{array}$ \\
\hline & $\begin{array}{l}\text { I read [Zoloft ads] and I look } \\
\text { at the fine print on those. And } \\
\text { it may actually be because l'm } \\
\text { taking the medication. [MP, } \\
\text { a } 30 \text {-year-old female } \\
\text { medication user] }\end{array}$ & $\begin{array}{l}\text { I'll look at the ad out of curiosity } \\
\text { of the negative side effects, and } \\
\text { look at it with a critical eye. Not } \\
\text { out of interest of taking drugs } \\
\text { myself, just curiosity. [LA, } 27 \text {-year- } \\
\text { old female magazine reader] }\end{array}$ & \\
\hline
\end{tabular}

Abbreviations: ADD, attention deficit disorder; DTCA, direct-to-consumer advertising.

closer ... but if I don't think I have the problem, I don't pay attention to it."

Other lay physicians read DTCA with others in mind. CT, a 41-year-old female antidepressant user, reads DTCA looking for "something a loved one might benefit from." CT says that she may help a loved one by offering them DTCA information, and "they may bring it to the doctor's attention and it may be something that gets prescribed. And ultimately it helps them." Additional quotations from lay physicians are located in Table 2.

\section{The informed shopper}

Informed shoppers read DTCA to assist in making important health care decisions, and look to DTCA for information about treatment options. This category is comprised of people who have diagnoses, already use antidepressant medications, and seek information about new or alternative drug therapies. There are two subtypes of informed shoppers. One subtype of informed shopper uses DTCA for rational purposes, attending to technical drug information, such as side effects and drug interactions. These shoppers use DTCA to learn about their medications and to compare benefits and risks associated with medications in the same class. Some rational informed shoppers read the "fine print" for medications they use. JJ, a 37-year-old female antidepressant user, relates, "I look at the pictures, but generally, if I'm on the medication, I'll look at the fine print." She uses the information to learn about her medication's side effects, efficacy, and interactions. Similarly, SR, an 18-year-old female antidepressant user, looks to DTCA to evaluate her treatment options. She says:

[DTCA] gives knowledge about the side effects so you can compare them and shop around. With the antidepressants, it helps you decide which one you should be on. It's always good to know what's out there. Your doctor doesn't always know if there's a better one. You need to know that there are other options. The more information, the better.

A second subtype uses DTCA for emotive purposes, seeking affirmation that they are using the right drug. Presumably, if DTCA lacked such affirmation, they would 
seek alternative drug therapies. KB, a 58-year-old female antidepressant user, reads DTCA for affirmation, and likes seeing her drug portrayed in DTCA: "I'm assured that it's a good drug because I see it advertised." Another male antidepressant user, 31-year-old BF, believes that DTCA portrayals can help decrease perceived stigma for medication users. He says, "If someone is on a medicine and they see 'normal' people [using it in DTCA], maybe that makes them feel like they're normal too." Additional quotations offered by informed shoppers can be found in Table 2 .

\section{The voyeur}

Voyeurs read DTCA as a way to learn about the world. Voyeurs do not necessarily imagine using the information to help others or themselves; rather, they are interested in learning about others' experiences through DTCA. There are two subtypes of voyeurs. One variety is empathetic about others' problems; s/he reads DTCA in order to learn about disorders and to better understand people who have affective disorders. Unlike lay physicians, voyeurs do not aim to label problems or encourage others to get treatment; they only wish to be more understanding of people's plight, and may use information to facilitate connectivity with those affected by disorders. MA, a 67-year-old female magazine reader, explains:

I read [DTCA] because I'm curious to learn [a drug's] application for what it does, and how it's used ... try to be more understanding of people. [DTCA] might help me recognize people who are in a depression. Maybe I can understand why they feel that way, and if they ask me for advice, maybe I can be some help.

A second variety of voyeur reads DTCA to satisfy curiosity about people's troubles. For instance, SS, a 36-yearold male antidepressant user, who works as a jail guard, acknowledges reading DTCA: "if I've seen the drug, like if I've passed the drug to [an inmate] at work, because I kind of wonder what they're for." Curious about his inmates' troubles, SS uses DTCA to take a glance into their lives. Table 2 contains additional quotations offered by voyeurs.

\section{The evader}

Those who claim to avoid DTCA do so for two distinct reasons. Some ignore DTCA because they believe the information is biased, and others are simply not interested in information about prescription drugs. Those who believe that advertisements contain biased information oftentimes seek health information from alternative sources, like the Internet or medical professionals. They are not disinterested in all health information; they simply do not trust information provided in DTCA. Thus, these evaders may be active consumers of other forms of health information. According to EB, a 41-year-old female antidepressant user, "I don't read [DTCA]. I wouldn't look at an ad to get information as to whether it's something I might have. I'd more inclined to ask a doctor or go online and do research."

A second variety of evader ignores DTCA because they find prescription drug information irrelevant. This is the message offered by LS, a 37-year-old male magazine reader: "I wouldn't read it. As soon as I figured out it was about a drug I'd move on, just because I'm not into buying a drug. I'm flipping that page." Table 2 contains additional quotations offered by evaders.

\section{Discussion}

Findings suggest that, contrary to previous concerns, ${ }^{10,12,15,16}$ consumers are much more than passive, gullible recipients of DTCA. Rather, a myriad of motivations and experiences shape consumers' interest in and desire to make sense of health information. These heterogeneous perceptions of DTCA result in a variety of outward responses. During this time when health information is readily available to consumers via the Internet, television, and magazines, the climate in which medical encounters transpire is rapidly changing. ${ }^{9-17}$ Results of this analysis allow speculation about the ways in which medical encounters may (or may not) be affected by health information in the public sphere.

In-depth interviews with 36 men and women resulted in four distinct consumer categories which are roughly distinguished into two groups: those interested in and receptive to DTCA information, and those who ignore the information or disparage DTCA as a source of health information (Table 2).

\section{DTCA readers}

Three categories of DTCA readers were identified, each of whom might bring DTCA information to the consultation in different ways. The lay physician uses DTCA as a tool to facilitate self-diagnose and lay-diagnose. It is expected that lay physicians are likely to bring DTCA information to their physicians (Table 3) because they believe they have a condition and might benefit from receiving a prescription drug. These consumers are swayed by advertising messages, glorify the promised rewards of medication use, may be likely to introduce this information into the consultation, and may seek to obtain a diagnosis and a specific medication. ${ }^{43}$

The informed shopper is slightly different in that $\mathrm{s} / \mathrm{he}$ is being treated for a condition and is interested in the promises 
Table 3 Expected utilization of direct-to-consumer advertising by consumer categories

\begin{tabular}{lllll}
\hline & DTCA readers & & Nonreaders \\
\cline { 2 - 3 } & Lay physician & Informed shopper & Voyeur \\
\hline Will seek care based on DTCA? & Yes & Yes & No & No \\
What information is of interest & Diagnostic criteria; & Side effects; & Diagnostic criteria; etiology; \\
& drug benefits & drug benefits & manifestation of disorder &
\end{tabular}

Abbreviation: DTCA, direct-to-consumer advertising.

and prospects of advertised products. Informed shoppers read DTCA because of their interest in products that may effectively help treat their conditions. Many informed shoppers read advertisements for medications they already use, for instance, reading the "fine print" to learn about their drugs" side effect profiles; others are interested in learning about their treatment options. Informed shoppers may be likely to approach their physicians with hopes of discussing treatment options, and comparative efficacy and side effect profiles for multiple medications (Table 3).

The voyeur seeks to learn about others' disorders and medications; s/he reads DTCA out of curiosity and not because it directly relates to her health needs. One subtype, the empathetic voyeur, does not wish to self-diagnose or lay diagnose; s/he uses DTCA to facilitate understanding, connectivity, and communication with people with affective disorders. While such consumers attend to information in DTCA, the likelihood of discussing the information with a physician is uncertain (Table 3).

A second subtype of voyeur reads DTCA as a way of learning about the world or out of curiosity about others' experiences. S/he seeks information for information's sake, is curious about the world around him/her, and sees DTCA as an avenue by which s/he can learn more about it. Curious voyeurs are not likely to bring DTCA information into medical encounters, or if they do, are likely do so as a form of small talk.

\section{DTCA nonreaders}

Evaders - consumers who avoid DTCA - are classified into two subtypes. One subtype of evader believes that DTCA is biased and regards DTCA as an inadequate source of information. These consumers tend to be activated about their health care, may seek information from other sources like the Internet or a physician, and may be likely to approach a physician with information and ideas about treatment - just not information that they gathered from DTCA (Table 3). They may, on the surface, appear like the lay physician, but clinicians should appreciate the differences between the two consumer categories. Clinicians will need to use different approaches when responding to the health information presented by these two distinct types of activated patients.

A second subtype of evader is simply not interested in information about prescription drugs and finds DTCA irrelevant to his/her needs and circumstances. Such consumers do not believe that prescription drug information is suited for consumer audiences; they are not receptive to the notion that they need a medication and identify no use for DTCA. These evaders will not bring DTCA information to the physician, and rely solely on the physician to provide knowledge about diseases and treatment options (Table 3).

\section{Conclusion}

Previous assumptions about consumers' receptivity to DTCA messages are far too limiting and negate the role of human agency and the view of consumers as active information processors. ${ }^{10,12,15,16}$ Though consumers may be highly aware of DTCA, they are also likely to be skeptical about advertising messages. ${ }^{22}$ Given the vast array of sources of health information, DTCA should be treated as one of several sources of information. One study showed that DTCA was a source of health information for many consumers, but it had less value than information from other sources such as family, friends, and doctors. ${ }^{20}$ Thus, the four categories identified herein can be applied to people accessing health information from other sources, like social networks or the Internet. Future research may involve the use of survey measures to confirm the distinctiveness of these categories and their relative presence among samples of patients, and may explore these prototypical responses in the context of other medications. Additionally, future research may focus on the ways in which DTCA affects clinical communication, prescription drug requests, and outcomes of clinical encounters.

Findings of this study suggest several clinical implications. First, it is important for physicians not to interpret the effect of DTCA as singular or necessarily powerful. Different types of patients will make sense of information in different ways depending on their needs, beliefs, and biases. Patients likely to take DTCA most seriously are those who are fearful of a particular health condition (the lay physician) or those 
pondering treatment alternatives (the informed shopper). For these patients, it will likely be best to address DTCA information with respect to underlying concerns (eg, an undiagnosed condition, dissatisfaction with current treatment) that prompted the introduction of the DTCA information into the consultation (Table 3). Thus, techniques to uncover and explore the patient's agenda would work well. ${ }^{44}$ Other patients may be interested in discussing DTCA information, but only as a topic of conversation or for general health education (voyeurs). Of importance here is not the information per se, but the opening for engaging the patient in a discussion.

In light of previous findings that clinicians oftentimes prescribe unnecessary medications that were discussed in medical encounters, ${ }^{16}$ it is suggested that clinicians should consider the range of possible motivations when patients discuss prescription drugs. Not all comments about medications should be taken as a request. Instead, patients' comments related to DTCA may be used as an opportunity to engage and understand patients' perspectives about illness and medication use, thus furthering the goal of providing patent-centered health care. ${ }^{45}$

This study makes an important contribution to the literature. It was found that consumers' responses to DTCA are not monolithic. This study is the first to the authors' knowledge to provide an analysis of consumers' value and use of DTCA from the consumers' perspective, thus providing a different view of the various ways people interact with DTCA, and the array of perceptions, biases, and motivations that guide consumers' behaviors. The study is limited in its focus on print DTCA. It is possible that consumers' utilization of and responses to DTCA in other media outlets, like television, do not coincide with the typology identified here. A second limitation involves the reliance on DTCA for antidepressant medications, as responses to antidepressant medications may be unique and consumers may utilize DTCA for other medications differently. Third, because this was an in-depth qualitative study of 36 interviews, the researchers did not have a sufficient sample to determine whether these categories varied by age, gender, and/or ethnicity; this should be a focus of future research. Finally, as is the case with all qualitative analysis, the study is limited by potential researcher bias in analysis of interview data and development of taxonomy.

\section{Acknowledgments}

Dr Arney would like to thank Dr Cecilia Menjivar (Arizona State University), Dr Rose Weitz (Arizona State University), Dr Victor Agadjanian (Arizona State University), and
Dr Adam Rafalovich (Pacific University) for their thoughtful review of prior versions of this work. This work was supported by the Division of Graduate Studies at Arizona State University and by the National Science Foundation's Division of Social, Behavioral, and Economic Sciences (Award ID 0828582, Dr Arney). Additional support was provided by the Houston VA HSR\&D Center of Excellence (HFP90020). Dr Naik received additional support from the National Institute on Aging (K23AG027144).

\section{Disclosure}

The authors report no conflicts of interest in this work. All patient/personal identifiers have been removed or disguised so the patients/persons described are not identifiable and cannot be identified through the details of the story. The views expressed in this article are those of the authors and do not necessarily represent the views of the Department of Veterans Affairs, National Science Foundation, or National Institute on Aging.

\section{References}

1. Morris LA, Brinberg D, Klimberg R, Rivera C, Millstein LG. The attitudes of consumers toward direct advertising of prescription drugs. Public Health Rep. 1986;101(1):82-89.

2. Perri M, Dickson WM. Direct to consumer prescription drug advertising: consumer attitudes and physician reaction. J Pharm Mark Manage. 1987;2(1):3-25.

3. Everett SE. Lay audience response to prescription drug advertising. J Advert Res. 1991;31(2):43-49.

4. Alperstein NM, Peyrot M. Consumer awareness of prescription drug advertising. J Advert Res. 1993;33:50-56.

5. Williams JR, Hensel PJ. Direct-to-consumer advertising of prescription drugs. J Health Care Mark. 1995;15:35-41.

6. Roth MS. Media and message effects of DTC prescription drug print advertising awareness. J Advert Res. 2003;43(2):180-193.

7. Aikin KJ, Swasy JL, Braman AC. Patient and Physician Attitudes and Behaviors Associated with DTC Promotion of Prescription Drugs - Summary of FDA Survey Research Results. Executive Summary. US Department of Health and Human Services; Food and Drug Administration; Center for Drug Evaluation and Research; 2004. Available from: http:// www.fda.gov/downloads/Drugs/ScienceResearch/ResearchAreas/DrugMarketingAdvertisingandCommunicationsResearch/UCM152890.pdf. Accessed September 3, 2009.

8. Murray E, Lo B, Pollack L, Donelan K, Lee K. Direct-to-consumer advertising: public perceptions on its effects on health behaviors, health care, and the doctor-patient relationship. J Am Board Fam Pract. 2004;17(1):6-18.

9. IMS Health. Majority of physicians have negative view towards DTC advertising [press release]. Fairfield, CT: IMS Health; September 15, 1998.

10. Hollon MF. Direct-to-consumer marketing of prescription drugs: creating consumer demand. JAMA. 1999;281(4):382-384.

11. Kopp SW, Bang HK. Benefit and risk information in prescription drug advertising: review of empirical studies and marketing implications. Health Mark Q. 2000;17(3):39-56.

12. Wilkes MS, Bell RA, Kravitz RL. Direct-to-consumer prescription drug advertising: trends, impact, and implications. Health Aff (Millwood) 2000;19(2):110-128.

13. Findlay SD. Direct to consumer promotion of prescription drugs. Economic implications for patients, payers, and providers. Pharmacoeconomics. 2001;19(2):109-119. 
14. Coney S. Direct-to-consumer advertising of prescription pharmaceuticals: a consumer perspective from New Zealand. J Public Policy Mark. 2002;21(2):213-223.

15. Lexchin J, Mintzes B. Direct-to-consumer advertising of prescription drugs: the evidence says no. J Public Policy Mark. 2002;21(2): 194-202.

16. Robinson AR, Hohmann KB, Rifkin JI, et al. Direct-to-consumer pharmaceutical advertising: physician and public opinion and potential effects on the physician-patient relationship. Arch Intern Med. 2004;164(4):427-432.

17. Weissman JS, Blumenthal D, Silk AJ, Zapert K, Newman KM, Leitman R. Consumers' reports on the health effects of direct-toconsumer advertising. Health Aff (Millwood). 2003;Suppl Web Exclusives:w3-82-95.

18. Murray E, Lo B, Pollack L, Donelan K, Lee K. Direct-to-consumer advertising: physicians' views of its effects on quality of care and the doctor-patient relationship. J Am Board Fam Pract. 2003;16(6):513-524.

19. Spence MM, Teleki SS, Cheetham TC, Schweitzer SO, Millares M. Direct-to-consumer advertising of COX-2 inhibitors: effect on appropriateness of prescribing. Med Care Res Rev. 2005;62(5):544-559.

20. Nagler RH, Gray SW, Romantan A, et al. Differences in information seeking among breast, prostate, and colorectal cancer patients: results from a population-based survey. Patient Educ Couns. 2010; 81 Suppl:S54-S62.

21. Grant AE. Dependency and control. Paper presented at: Annual Convention of the Association for Education in Journalism and Mass Communications; August 5-8, 1998; Baltimore, MD.

22. Bell RA, Taylor LD, Kravitz RL. Do antidepressant advertisements educate consumers and promote communication between patients with depression and their physicians? Patient Educ Couns. 2010;81(2):245-250.

23. Bruera E, Willey JS, Palmer JL, Rosales M. Treatment decisions for breast carcinoma: patient preferences and physician perceptions. Cancer. 2002;94(7):2076-2080.

24. van Wieringen JC, Harmsen JA, Bruijnzeels MA. Intercultural communication in general practice. Eur J Public Health. 2002;12(1):63-68.

25. Jackson JL. Communication about symptoms in primary care: impact on patient outcomes. J Altern Complement Med. 2005;11(Suppl 1): S51-S56.

26. Staiger TO, Jarvik JG, Deyo RA, Martin B, Braddock CH 3rd. Patientphysician agreement as a predictor of outcomes in patients with back pain. J Gen Intern Med. 2005;20(10):935-937.

27. Street RL Jr, Haidet P. How well do doctors know their patients? Factors affecting physician understanding of patients' health beliefs. J Gen Intern Med. 2011;26(1):21-27.

28. Abraham NS, Naik AD, Street RL Jr. Shared decision making in GI clinic to improve patient adherence. Clin Gastroenterol Hepatol. 2012;10(8):825-827.
29. Naik AD, Kallen MA, Walder A, Street RL Jr. Improving hypertension control in diabetes mellitus: the effects of collaborative and proactive health communication. Circulation. 2008;117(11):1361-1368.

30. Street RL Jr, Makoul G, Arora NK, Epstein RM. How does communication heal? Pathways linking clinician-patient communication to health outcomes. Patient Educ Couns. 2009;74(3):295-301.

31. Niederdeppe J, Hornik RC, Kelly BJ, et al. Examining the dimensions of cancer-related information seeking and scanning behavior. Health Commun. 2007;22(2):153-167.

32. Coleman JS. Relational analysis: the study of social organization with survey methods. Hum Organ. 1958;17:28-36.

33. Erickson BH. Some problems of interference from chain data. In: Schuessler KF, editor. Sociological Methodology. San Francisco, CA: Jossey-Bass Publishers; 1979;10:276-302.

34. Heckathorn DD. Respondent-driven sampling II: deriving valid population estimates from chain-referral samples of hidden populations. Soc Probl. 2002;49(1):11-34.

35. Salganik MJ, Heckathorn DD. Sampling and estimation in hidden populations using respondent-driven sampling. Sociol Methodol. 2004;34(1):193-240.

36. Watters JK, Biernacki P. Targeted sampling: options for the study of hidden populations. Soc Probl. 1989;36(4):416-430.

37. Glaser BG, Strauss AL. The Discovery of Grounded Theory: Strategies for Qualitative Research. Chicago, IL: Aldine; 1967.

38. Glaser BG. Theoretical Sensitivity: Advances in the Methodology of Grounded Theory. Mill Valley, CA: Sociology Press; 1978.

39. Strauss AL, Corbin J. Basics of Qualitative Research: Grounded Theory Procedures and Techniques. Newbury Park, CA: Sage Publications; 1990.

40. Naik AD, Schulman-Green D, McCorkle R, Bradley EH, Bogardus ST Jr. Will older persons and their clinicians use a shared decision-making instrument? J Gen Intern Med. 2005;20(7):640-643.

41. Brown VA, Bartholomew LK, Naik AD. Management of chronic hypertension in older men: an exploration of patient goal-setting. Patient Educ Couns. 2007;69(1-3):93-99.

42. Morse JM. The significance of saturation. Qual Health Res. 1995;5: $147-149$.

43. Weissman JS, Blumenthal D, Silk AJ, et al. Physicians report on patient encounters involving direct-to-consumer advertising. Health Aff (Millwood). 2004;Suppl Web Exclusives:W4-219-233.

44. Street RL Jr, Gordon HS, Ward MM, Krupat E, Kravitz RL. Patient participation in medical consultations: why some patients are more involved than others. Med Care. 2005;43(10):960-969.

45. Frankel RM, Stein T. Getting the most out of the clinical encounter: the four habits model. J Med Pract Manage. 2001;16(4):184-191.
Patient Preference and Adherence

\section{Publish your work in this journal}

Patient Preference and Adherence is an international, peer-reviewed, open access journal focusing on the growing importance of patient preference and adherence throughout the therapeutic continuum. Patient satisfaction, acceptability, quality of life, compliance, persistence and their role in developing new therapeutic modalities and compounds to

\section{Dovepress}

optimize clinical outcomes for existing disease states are major areas of interest. This journal has been accepted for indexing on PubMed Central. The manuscript management system is completely online and includes a very quick and fair peer-review system. Visit http://www.dovepress.com/ testimonials.php to read real quotes from published authors. 